Nordic Concrete Research - Publ. No. NCR 61 - ISSUE 2 / 2019 - Article 6, pp. 91-106

\begin{tabular}{|l|r|}
\hline \multicolumn{1}{|c|}{ S sciendo } & \begin{tabular}{c} 
NCF $\begin{array}{l}\text { Nordic } \\
\text { Concrete } \\
\text { Federation }\end{array}$ \\
\hline $\begin{array}{l}\text { C) Article authors. This is an open access article distributed under } \\
\text { the Creative Commons Attribution-NonCommercial-NoDerivs } \\
\text { licens. (http://creaticecommons.org/licenses/by.nc-nd/3.0/). }\end{array}$
\end{tabular} \\
\hline & $\begin{array}{r}\text { ISSN online 2545-2819 } \\
\text { ISSN print } \quad \text { 0800-6377 }\end{array}$ \\
DOI: $10.2478 /$ ncr-2019-0010 & $\begin{array}{r}\text { Received: April 2, 2019 } \\
\text { Revision received: Nov. 22, 2019 }\end{array}$ \\
& Accepted: Nov. 27, 2019 \\
\hline
\end{tabular}

\title{
Freeze-thaw Damage Dependence on Wind-driven Rain of Outdoor Exposed Concrete - A Case Study
}

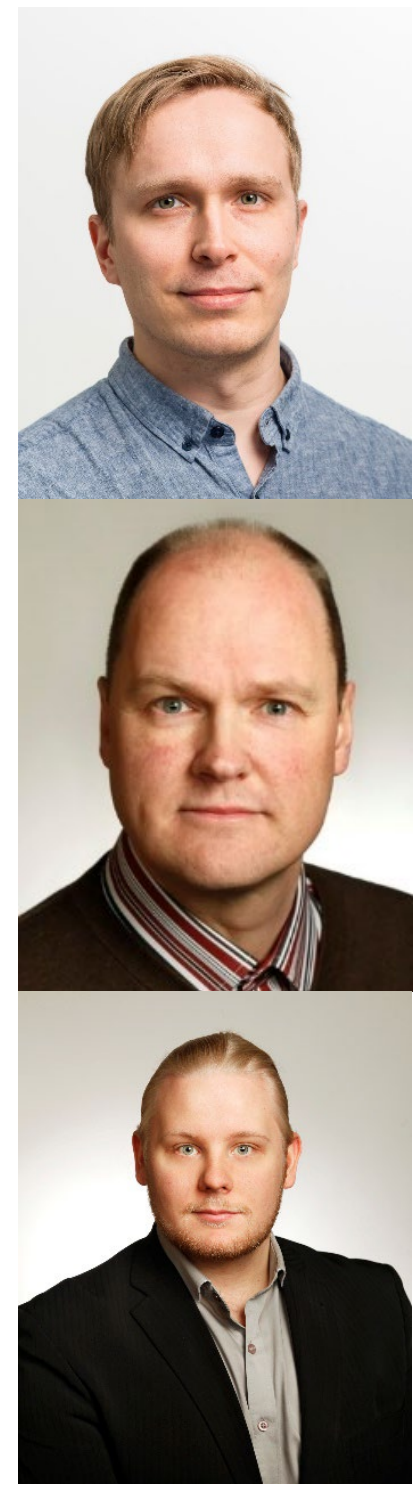

Toni A. Pakkala

M.Sc.

PhD student

Tampere University, Civil Engineering P.O. Box 600, 33014 Tampere, Finland toni.pakkala@tuni.fi

Jukka Lahdensivu

D.Sc.

Adjunct Professor

Tampere University, Civil Engineering P.O. Box 600, 33014 Tampere, Finland jukka.lahdensivu@tuni.fi

Petteri Huuhka

M.Sc.

Tampere University, Civil Engineering P.O. Box 600, 33014 Tampere, Finland petteri.huuhka@ramboll.fi 


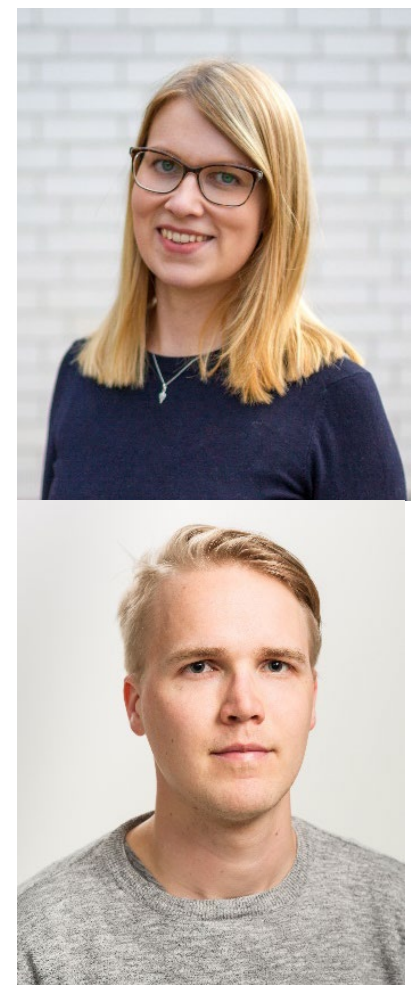

Henna Kivioja

M.Sc.

Project Researcher

Tampere University, Civil Engineering

P.O. Box 600, 33014 Tampere, Finland

henna.kivioja@tuni.fi

\author{
Antti-Matti Lemberg \\ B.Sc. \\ Research Assistant \\ Tampere University, Civil Engineering \\ P.O. Box 600, 33014 Tampere, Finland \\ antti-matti.lemberg@tuni.fi
}

\begin{abstract}
It has been shown in previous studies that the existing precast concrete element building stock in Finland has quality issues, especially with freeze-thaw durability and reinforcement corrosion. In addition, it has been presented that deterioration rate is the fastest in coastal area and decreases towards north which has been supposed to be a reason of lower amount of wind-driven rain (WDR). The aim of this study was to examine the connection between the amount of WDR on structures and the freeze-thaw damage more comprehensively. Condition investigation reports of 472 precast concrete element buildings were reanalysed to study the relation and the results were compared to climate data of the same time period to study the correlation between condition investigation observations and the amount of WDR. In addition, the observations made in a condition investigations and their relation to climate load at the same building were studied as a case study. The results show that there is a significant connection between the WDR related climate load and the freeze-thaw damage occurrence. The results can be used to plan protective methods and be a base for service life estimations.
\end{abstract}

Key words: Concrete, climatic stress, freeze-thaw attack, service life, durability properties. 
1.

1.1

INTRODUCTION

Previous studies [1-3] have shown that the deterioration rate of outdoor exposed concrete structures in Finland is highly dependent on geographical location and the direction in which the structure faces. Pakkala et al. [2] presented that the severity of the freeze-thaw attack is heavier in coastal areas, leading to faster freeze-thaw damage. In a recent study, Pakkala et al. [3] presented that the corrosion rate in carbonated concrete is significantly higher in coastal areas than in other locations and for south-west-, south- and south-east-facing structures.

The deterioration itself and the rate of it are always linked to a combination of harsh environmental stress, inadequate structural properties and the poor durability properties and/or ageing of the used material. If one of them is excluded, there will be no deterioration. The Finnish climate is quite harsh for porous building materials such as concrete and masonry because of quite high winddriven rain (WDR) amounts with almost perennial potential for freeze-thaw cycles while, especially during autumn, the possibilities for structures to dry are poor [2,3]. In addition, the existing concrete building stock has been shown to have large variation in quality because of lack of knowledge and regulation during its construction [1]. It has also been shown that, even since regulation based on current knowledge, the quality of concrete construction has not been up to standard [2].

Since the 1990s, the state of Finnish concrete facades and balconies has been followed extensively through systematic condition investigations. In addition, he connection between the deterioration of existing concrete structures and environmental stress has been studied quite comprehensively, especially the effect of climatic conditions on the corrosion of reinforcement $[1,3,4]$.

Both globally and in Finland, studies connecting freeze-thaw deterioration and actual climatic stress have been rare and mostly focused on the annual number of freeze-thaw cycles. Lisø et al. [5] presented a combination of frost decay exposure index (FDEI) and freezing point crossings (FPC) to characterise the risk of freeze-thaw damage to a porous, mineral material in a given climate. In their studies, the freeze-thaw cycles were considered as temperature crossings over freezing point $\left(0{ }^{\circ} \mathrm{C}\right)$ and the number of cycles was defined as annual average number of days with freezing point crossings.

The FDEI links average annual freezing point crossings (FPC) to the amount of liquid precipitation recorded from the day an FPC has occurred and the preceding two, three or four days. When the FDEI and FPC are shown in the same diagram, the risk of frost decay can be estimated by analysing their relation. For example, if the amount of FPCs is high but the amount of precipitation before the crossings is low, i.e. FDEI is low, the risk of frost decay is relatively low, but if they both are high, the risk is considerable. Later Pakkala et al. [2] made similar studies in Finnish climate with different freezing point temperatures $\left(-5^{\circ} \mathrm{C}\right.$ and $\left.-10^{\circ} \mathrm{C}\right)$.

\section{2}

\section{Scope of the study}

The mechanism of freeze-thaw damage of concrete and the role of the amount pore water is well known [1]. However, there has been lack of studies connecting the actual amount of WDR on structures and the freeze-thaw damage. The objective of this research was to study more deeply the known connection between the amount of WDR and freeze-thaw damage by assessing if it is 
possible to estimate the freeze-thaw stress level by the amount of WDR. The research includes assessment of the results of condition investigation reports and a case study where the amount of WDR on the facades of an existing building is modelled.

2.

\section{BACKGROUND}

\subsection{Condition investigation of concrete structures}

The condition of Finnish concrete facades and balconies is systemically investigated according to national guideline [6]. Lahdensivu et al. [7] have presented the methods based on this guideline. The aim of the investigation is to produce information about the state of the structures for owners to plan the timing of possible repairs.

As summarised, a condition investigation includes the study of preliminary information (design plans, site visit), the determination of potential degradation mechanisms, the planning of necessary sampling, the assembly of gathered information and its analysis and reporting. The gathering of information during the investigation includes both non-destructive (NDT) and destructive methods. The NDT methods usually include visual inspection and cover depth measurements of the reinforcement and hammering of the structures. The hammering is based on sound difference between the degraded and solid concrete. When hammered, the degraded concrete has a softer sound than solid concrete and can be detected easily, especially by comparing the sound to solid concrete, which is usually always available nearby. In addition to the overall view, the NDT methods are used to target the sampling. For example, if visual inspection or hammering indicate freeze-thaw damage, there is no need to take the sample directly from the deteriorated structure. Instead, the sampling should be conducted close to the damaged structure to investigate the extent of the damage. [6,7]

The destructive methods usually include an extensive amount of drilled concrete core samples and drill cuttings. The samples are inspected visually to determine the aggregate size and distribution, carbonation depth, compaction of the concrete, visible cracking or any other deterioration and the location and size of reinforcement. After the visual inspection, some of the samples are studied more thoroughly by thin-section analysis. The rest of the samples are used to determine the protective pore ratio and tensile strength, which both give inaccurate yet utilizable information about the quality of concrete and possible freeze-thaw damage. The drill cuttings are used to study the amount of chlorides in the cement paste. [6,7]

\section{2}

Freeze-thaw damage in Finnish concrete structures

According to Kuosa \& Vesikari [8], there are more than 15 different theories or explanations for freeze-thaw attack on porous materials. However, in all of them the amounts of moisture and water play a key role. Probably the most widely known theory for freeze-thaw damage is the hydraulic pressure theory by Powers [9]. It suggests that freezing water expands creating pressure in the pore structure, forcing the unfrozen water out of the pore, and thus causing localised internal tensions in the material. Litvan [10] presented that the water in the pore structures of a porous material does not freeze immediately as the temperature drops below $0^{\circ} \mathrm{C}$. Freezing happens first in larger capillary pores. In smaller gel pores, the water begins to freeze when the temperature is around -15 to $-20^{\circ} \mathrm{C}$. According to Pigeon \& Pleau [11], $-5^{\circ} \mathrm{C}$ can be considered the limiting temperature for a concrete pore structure to be exposed to freeze-thaw damage. 
Freeze-thaw damage in outdoor exposed structures can be avoided using methods based on structural or material properties. Structural methods are based on sheltering or covering the material from moisture and direct water contact. In most cases, this is neither possible nor economical. The most effective methods by material properties are air-entrainment and increasing the strength of the concrete. Increasing the strength of the concrete prevents the freeze-thaw damage in two ways: the higher strength can tolerate the forces caused by the pressure of expanding water during freezing, and it usually results in a lower water-cement ratio, which leads to lower porosity, i.e. denser concrete.

Air-entrainment is based on protective pores where the pressure caused by freezing water can discharge. The protective pores achieved by the air-entrainment are round air voids with specific diameter and distribution. While the diameter of normal air voids occurring in cement paste differ from $10 \mu \mathrm{m}$ to over $1 \mathrm{~mm}$, an optimal diameter of protective pores are referred to be $50 \ldots 300 \mu \mathrm{m}$ and they should locate less than $400 \mu \mathrm{m}$ of each other [11]. In Finland, it has been recommended in outdoor structures since 1976, and became mandatory in 1980 by virtue of the Finnish Concrete Code. The success of air-entrainment can be presented by a protective pore ratio $p_{r}$, see Equation 1 , or more precisely by the spacing factor.

The protective pore ratio indicates the volumetric ratio of protective pores compared to all the pores without taking a stand on the distribution of the protective pores. In the protective pore ratio test, the concrete sample is first slowly immersed in water to fill the capillary pores. Then the sample is oven-dried. In the last step, a vacuum is used to fill also the protective pores, which do not fill up capillary. The protective pore ratio can be calculated by the ratio of the weight measurements as follows:

$$
p_{r}=\frac{\left(m_{v}-m_{c}\right)}{\left(m_{v}-m_{d}\right)}
$$

where $m_{v}$ is the mass of a water saturated concrete sample after vacuum exposure, $m_{c}$ is the mass of the sample after capillary suction and $m_{d}$ is the dry mass of the sample after oven-drying.

Lahdensivu [1] presented that the porosity protection of Finnish concrete facades can be considered quite inadequate, both in facades and in the balcony structures of concrete-element buildings built between 1960 and 1997. For example, almost 50\% of facades with exposed aggregate, clinker-clad, painted and plain concrete surfaces had a protective pore ratio of less than 0.10 . In balconies, the numbers are even higher while $70 \%$ of side panels, $60 \%$ of slabs and $50 \%$ of parapets had a ratio under 0.10 . In their study, Pakkala et al. [2] presented that, even in buildings built after 1990, i.e. the modern requirement for protective pore ratio, only approx. $50 \%$ of precast panels and less than $60 \%$ of balcony structures met the freeze-thaw resistance requirements.

The spacing factor indicates the average of half the distance between protective pores and can only be detected by microscope based on a standard ASTM C856-18A [12]. In the highest exposure class, the protective pore ratio of 0.15 was recommended in the Concrete Code in 1976 and regulated in 1980. The requirement of 0.20 was presented in the Concrete Code of 1989. Based on a number of thin-section analyses Koskiahde [13] presented that the protective pore ratio of 0.20 corresponds to a spacing factor of $0.25 \mathrm{~mm}$ if the protective pores are rather evenly distributed. In 2004, the spacing factor of $0.25 \mathrm{~mm}$ was made as a requirement because the spacing factor takes into account also the distribution of the pores. Nowadays the spacing factor requirement is related to exposure class where the lowest requirement is $\leq 0.27 \mathrm{~mm}$ in exposure class XF1 with a designed service life of 50 years. Lahdensivu [1] presented that a protective pore 
ratio of $<0.10$ can be considered to make concrete resistant to freeze-thaw in the Finnish outdoor climate.

Lahdensivu [1] presented that, in structures with inadequate air-entrainment, it has taken on average 307 freeze-thaw cycles (limiting temperature $-5^{\circ} \mathrm{C}$ ) for up to three days after a rain event in a coastal area and 388 cycles inland for incipient freeze-thaw damage to occur in thin-section analysis. The incipient freeze-thaw damage was classified based in classification by Koskiahde [13] as a cracking with width less than $0.01 \mathrm{~mm}$ and length less than $10 \mathrm{~mm}$. The numbers were calculated by singling out each case where incipient freeze-thaw damage was detected in condition investigations and calculating the amount of freeze-thaw cycles after a rain event from climate data of the nearest weather station available in the study. The lowest numbers of freezethaw cycles where incipient freeze-thaw damage was detected were 210 and 270, respectively. Shang et al. [14] showed by laboratory freeze-thaw testing of concrete with similar entrained air content than used in Finland that even air-entrained concrete with a strength class of C50 eventually suffers from strength loss. In their studies, it was found that while C20 lost 50\% of its compressive strength after 300 fast freeze-thaw cycles, C40 and C50 lost 10\%. The non-airentrained concrete degraded before 50 fast freeze-thaw cycles. However, the accelerated freezethaw testing in laboratory is more severe than exposure in outdoor conditions and thus is not directly comparable to actual deterioration rate.

\section{3.}

\section{RESEARCH METHODS AND MATERIAL}

\section{1}

\section{Condition investigation database}

The research material is based on a BeKo (Repair strategies of concrete facades and balconies) research conducted by TUT between 2006-2009 [15]. The research collected a comprehensive database based on condition investigation reports of 947 concrete element buildings. The database consists of the degradation-related material properties of the structures including porosity, tensile strength, the carbonation depth of the concrete, the cover depths of reinforcement and the observed degradation in visual inspection and thin-section analysis done in a laboratory. However, the data based on freeze-thaw damage detected with hammering were not collected in the database to the same accuracy as other properties. The main reason was that the information based on freezethaw damage observations was not systemically or extensively presented in the reports. That has led to imprecise data about the far-advanced freeze-thaw damage lacking for example the facing directions of the observations.

In this study, 244 condition investigation reports from the BeKo database were reanalysed including the investigation of 472 concrete element buildings. Every mention of freeze-thaw damage in facades or balcony structures and the direction in which the structure was facing was recorded. Far-advanced freeze-thaw damage was mentioned in façade structures in 93 reports and in 68 of those cases, the facing direction could be identified. In balconies, the same figures were 101 and 74, respectively. In 13 cases in facades, far-advanced freeze-thaw damage was reported on two, and in two cases on three different facades, i.e. the total number of far-advanced freezethaw observations was 85 . In balcony structures, far-advanced freeze-thaw damage was recorded in structures facing in two different directions in eight of the cases, resulting in a total of 82 observations.

The buildings were located geographically in four different areas based on climatic conditions and population concentration: a coastal area, southern Finland, inland and Lapland (northern 
Finland). The background for dividing the buildings this way can be found in [16]. Far-advanced freeze-thaw damage was reported so that the direction of facing could be identified in facades in 42 cases in coastal area, 26 cases in southern Finland and 25 cases in inland. The same numbers with the balcony structures were 43, 42 and 15, respectively. Only one of the studied buildings where far-advanced freeze-thaw damage was reported was located at Lapland, so Lapland is not presented separately in the results.

The existence or success of air-entrainment was evaluated in 425 of the 472 studied buildings based on both the protective pore ratio and the spacing factor. In $11 \%$ of all measurements, the air-entrainment was stated as sufficient, in $81 \%$ insufficient and in $8 \%$ both. When considering only the cases where far-advanced freeze-thaw damage was observed, the share was $3 \%, 93 \%$ and $5 \%$, respectively.

\section{2}

\section{Weather data}

A standard SFS-EN ISO 15927-3 [17] was used to estimate the WDR on different parts of the facades and balconies. The standard presents a wall annual index IWA that takes into account the amount of rain, the effect of wind during the rain event, the roughness of the terrain near the studied building, topography, obstacles such as other buildings and the height level of the studied spot on the wall. The index is calculated as follows:

$$
I_{W A}=I_{A} C_{R} C_{T} O W
$$

where $I_{A}$ is the airfield annual index, $C_{R}$ is the terrain roughness coefficient, $C_{T}$ is the topography coefficient, $O$ the obstruction factor and $W$ the wall factor. The airfield annual index $I_{A}$ is defined as:

$$
I_{A}=\frac{2}{9} \frac{\sum v r^{\frac{8}{9}} \cos (D-\theta)}{N}
$$

where $v$ is the hourly mean wind speed $[\mathrm{m} / \mathrm{s}], r$ is the hourly rainfall total $[\mathrm{mm}], D$ the hourly mean wind direction from north $\left[{ }^{\circ}\right], \theta$ is the wall orientation relative to north $\left[{ }^{\circ}\right]$, and $N$ the number of years for which data are available, and the summation is taken over all hours for which $\cos (D-\theta)$ is positive. The roughness coefficient depends on the height above the ground and the roughness of the terrain in the direction from which the wind is coming. The coefficient $C_{R}$ at height $z$ is calculated as follows:

$$
\begin{aligned}
& C_{R}(z)=K_{R} \ln \left(\frac{z}{z_{0}}\right), \text { for } z \geq z_{\text {min }} \\
& C_{R}(z)=C_{R}\left(z_{\text {min }}\right), \text { for } z<z_{\text {min }}
\end{aligned}
$$

where $K_{R}$ is a terrain factor, $z_{o}$ is roughness length and $z_{\min }$ minimum height. The parameters depend on the terrain category, which in this study is category III: suburban or industrial areas and permanent forests.

The climate data for the four regions are collected from coastal area (Helsinki-Vantaa Airport), southern Finland (Jokioinen), inland (Jyväskylä) and Lapland (Sodankylä).

\section{3}

\section{Case building}

A case study was made to examine if a basic climate load study could be used when planning the condition investigation and especially the sampling. The case study building was chosen from the 
investigation reports as a representative for a typical suburban concrete apartment building with insufficient freeze-thaw durability properties and extensive collected data. The case study building is located in the city of Tampere, southern Finland. The 14-storey apartment building was built in 1977 and is made of precast concrete elements with exposed aggregate concrete surfaces. The building is located in an enclosed block surrounded by a low office building and multi-storey apartment buildings (Figure 1). The balconies are located on southeast-, south-westand north-east-facing facades.

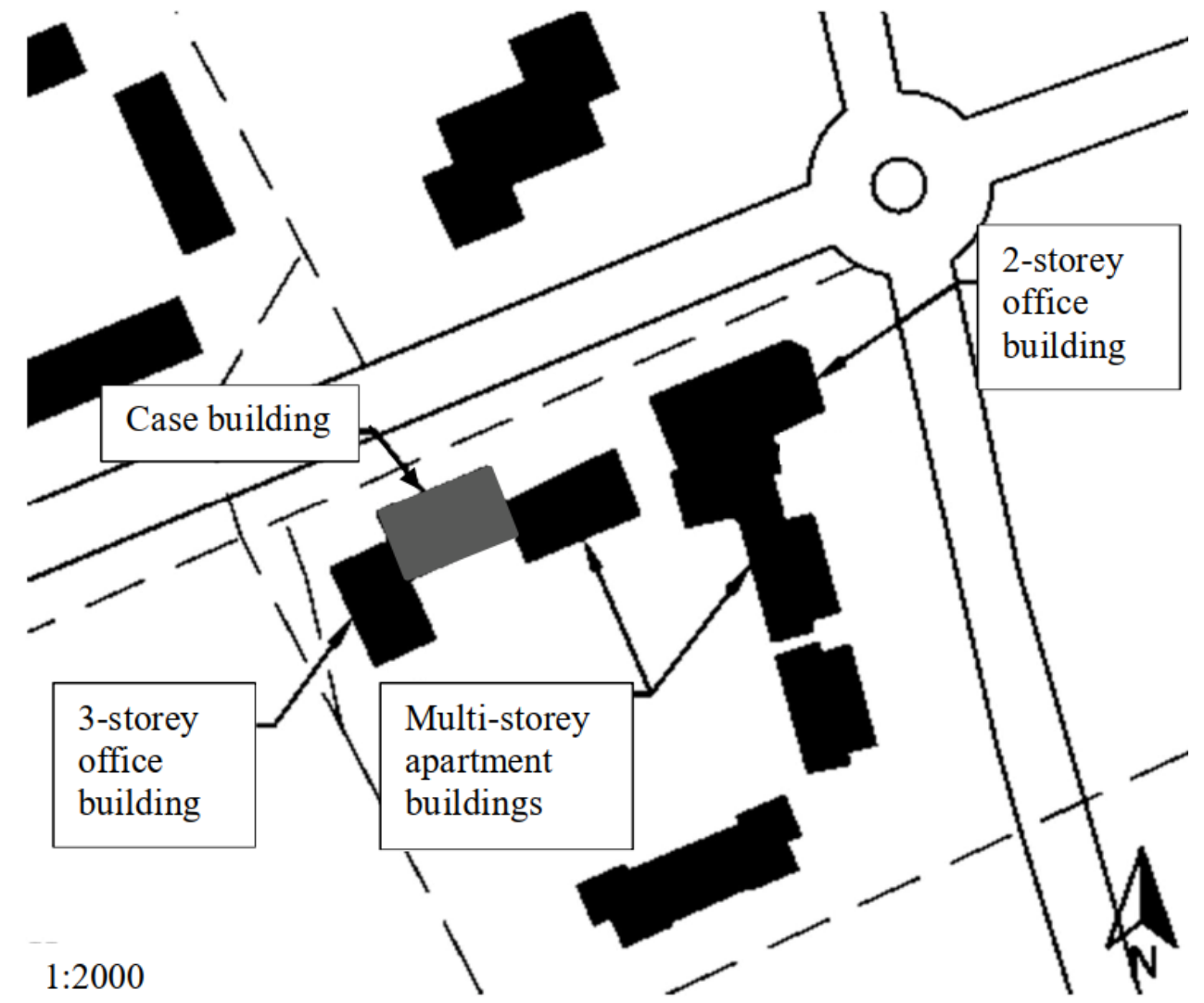

Figure 1-Geography of case building in the block.

The condition investigation was made 1997 (when the building was 20 years old) and presented in 1998. The condition investigation included NDT methods (visual inspection and hammering), 10 concrete core samples from facades and 17 samples from balconies. Results from both the laboratory measurements and NDT methods are used in this study.

The weather data used in the case study are from Jokioinen, located approx. $70 \mathrm{~km}$ from the case building. The weather data includes data collected every 3 hours (converted to hourly data) from 1970 to 2009 including temperature, amount of rain, wind speed and solar radiation from 1980 to 2009. The data were used to estimate the total amount of WDR to facades and balconies from 1980 to 1997 (year of condition investigation). There was no access to weather data from 1977 to 1980, which is why data from the first years of the building are not included in calculations.

The parameters used are listed in Table 1. 
Table 1 - Location- and orientation-dependent values used in this study.

\begin{tabular}{|c|c|c|c|c|}
\hline Parameter & \multicolumn{4}{|c|}{ Value } \\
\hline$C_{T}$ & \multicolumn{4}{|c|}{1} \\
\hline$W$ & \multirow{2}{*}{\multicolumn{4}{|c|}{$\begin{array}{l}\text { Top } 2.5 \mathrm{~m}: 0.5 \\
\text { Rest of the wall: } 0.2\end{array}$}} \\
\hline$W$ & & & & \\
\hline$K_{R}$ & \multicolumn{4}{|c|}{0.22} \\
\hline$z_{0}$ & \multicolumn{4}{|c|}{0.3} \\
\hline \multirow[t]{3}{*}{$z_{\min }$} & \multicolumn{4}{|c|}{8} \\
\hline & \multicolumn{4}{|c|}{ Wall orientation } \\
\hline & "North-west" & "North-east" & "South-east" & "South-west" \\
\hline$\theta$ & $340^{\circ}$ & $70^{\circ}$ & $160^{\circ}$ & $250^{\circ}$ \\
\hline$O$ & 0.7 & 0.2 & 0.7 & 1.0 \\
\hline
\end{tabular}

In this case, $N$ was chosen at 1 to sum up all the WDR, which has precipitated on the studied structures from the earliest available weather data to the time of the condition investigation. The wall annual index $I_{W A}$ was then calculated at variable height $z$ in all the facades. The summed amount of $I_{W A}$ was then compared to the observations made in the condition investigation.

4. RESULTS AND DISCUSSION

\section{1} Far-advanced freeze-thaw damage in database

Based on the condition investigation reports, $81 \%$ of far-advanced freeze-thaw damage was located in west-, south-west-, south- and south-east-facing facades. Based on the geographical location, the shares are $88 \%, 83 \%$ and $70 \%$ in the coastal area, southern Finland and inland, respectively. In balconies, the share is $84 \%$. However, with balconies it must be taken into account that most of them are located on western and southern facades to maximise the daylight and evening sun. The distribution of observed far-advanced freeze-thaw damage in facades and balconies is presented in Figures 2 and 3, respectively.

Figure 4 shows Airfield annual index $I_{A}$ to represent WDR from different directions, and Figure 5 shows $I_{A}$ from different directions for up to three days before freeze-thaw cycles with a limiting temperature of $-5{ }^{\circ} \mathrm{C}$. The share of WDR from the west, south-west, south and south-east is $65 \%$ of all WDR. The share of WDR before freeze-thaw events is $78 \%$ and, when separated into coastal area, southern Finland and inland, it is $81 \%, 79 \%$ and $71 \%$, respectively. 
Nordic Concrete Research - Publ. No. NCR 61 - ISSUE 2 / 2019 - Article 6, pp. 91-106

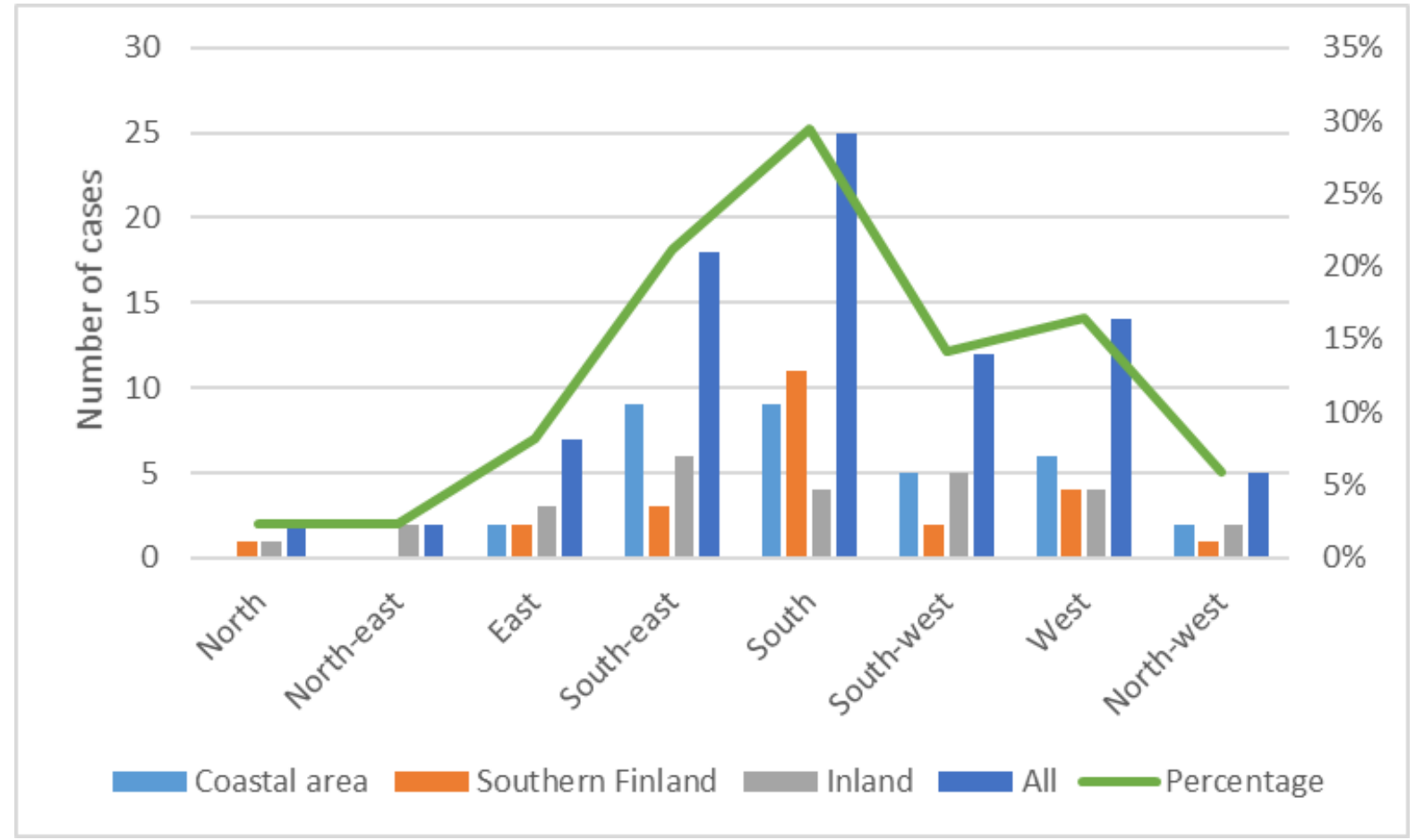

Figure 2 - Far-advanced freeze-thaw damage observed in facades based on the condition investigation data.

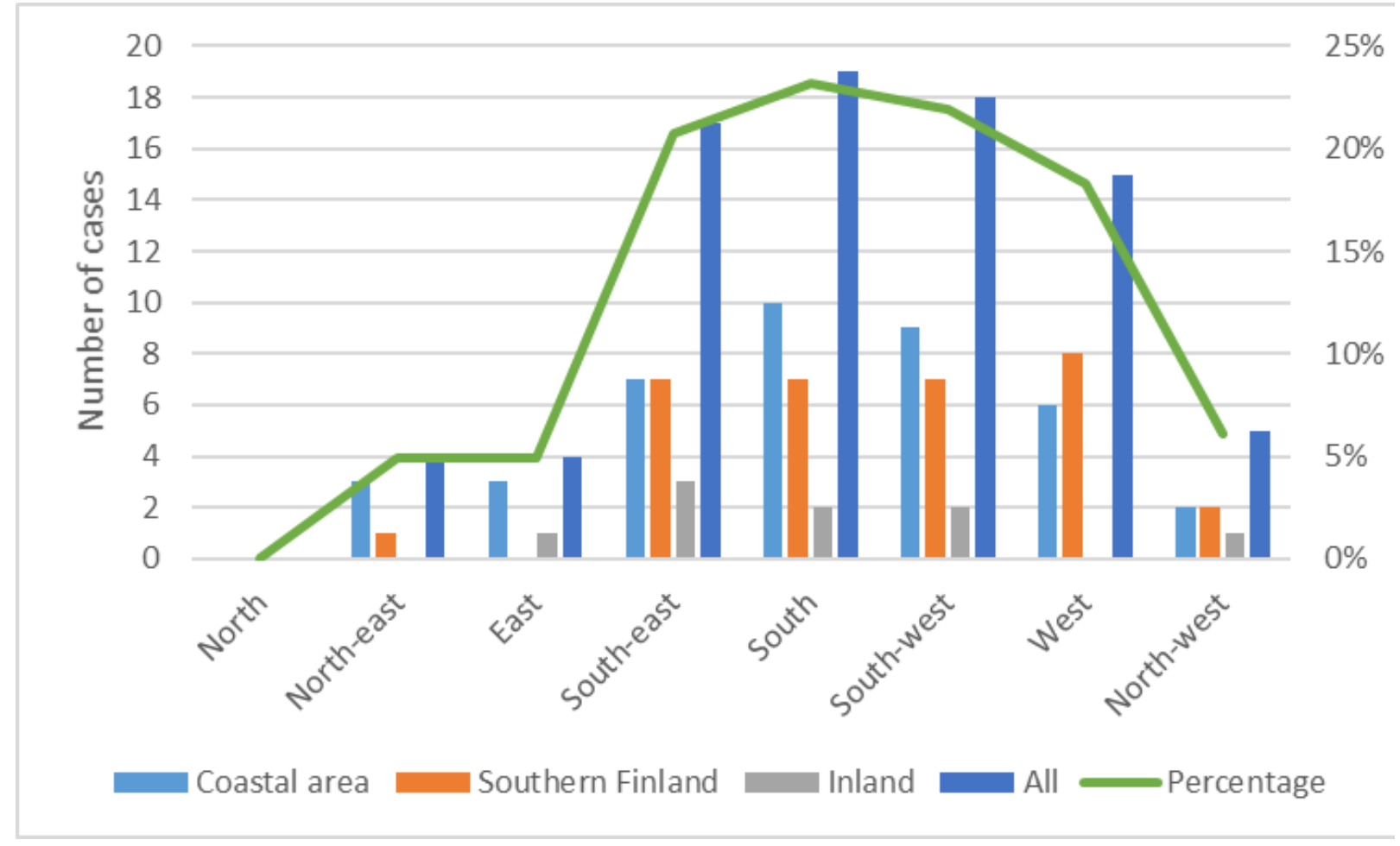

Figure 3 - Far-advanced freeze-thaw damage observed in balconies based on the condition investigation data. 
Nordic Concrete Research - Publ. No. NCR 61 - ISSUE 2 / 2019 - Article 6, pp. 91-106

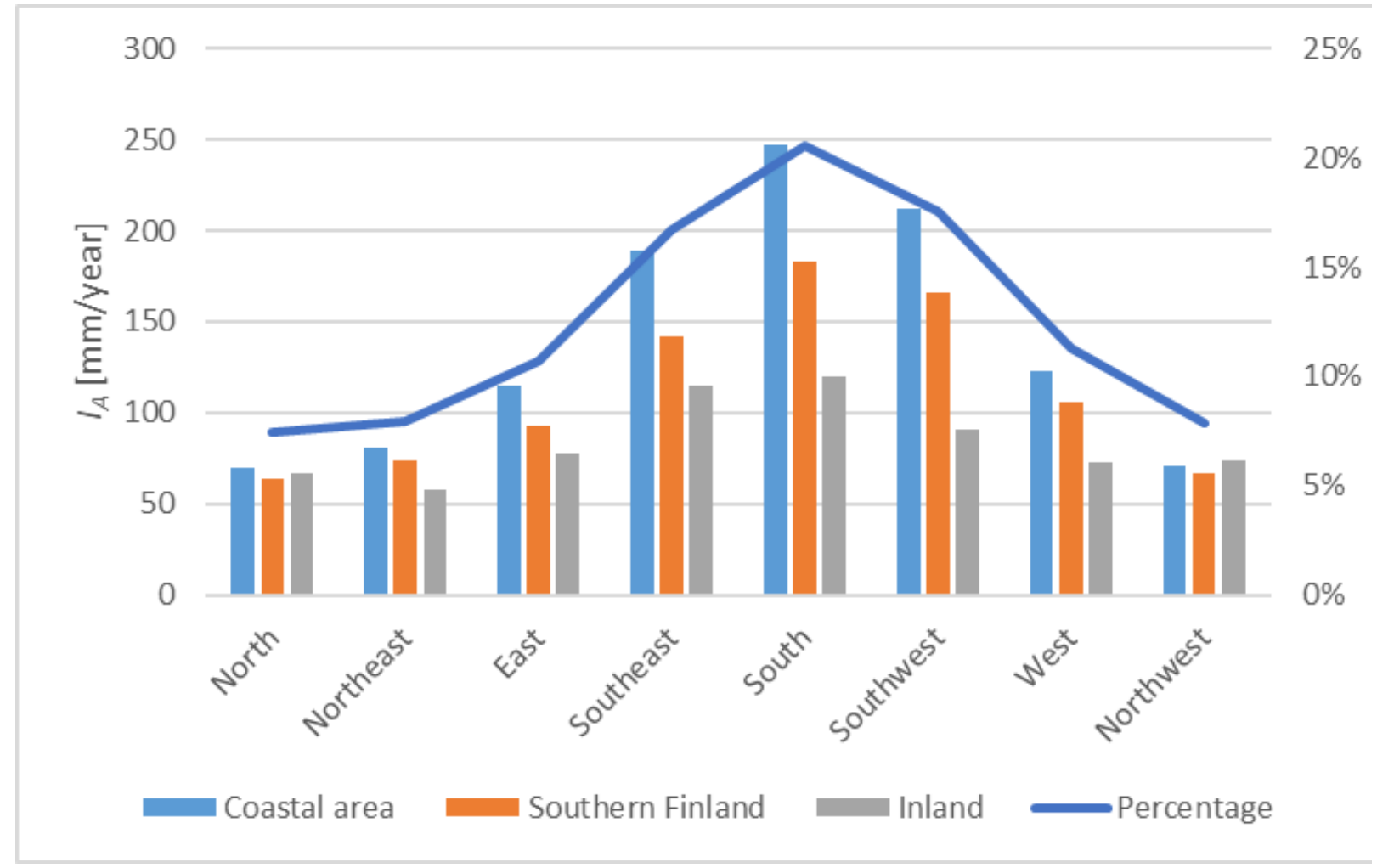

Figure 4 - Airfield annual index from different directions at the three locations studied.

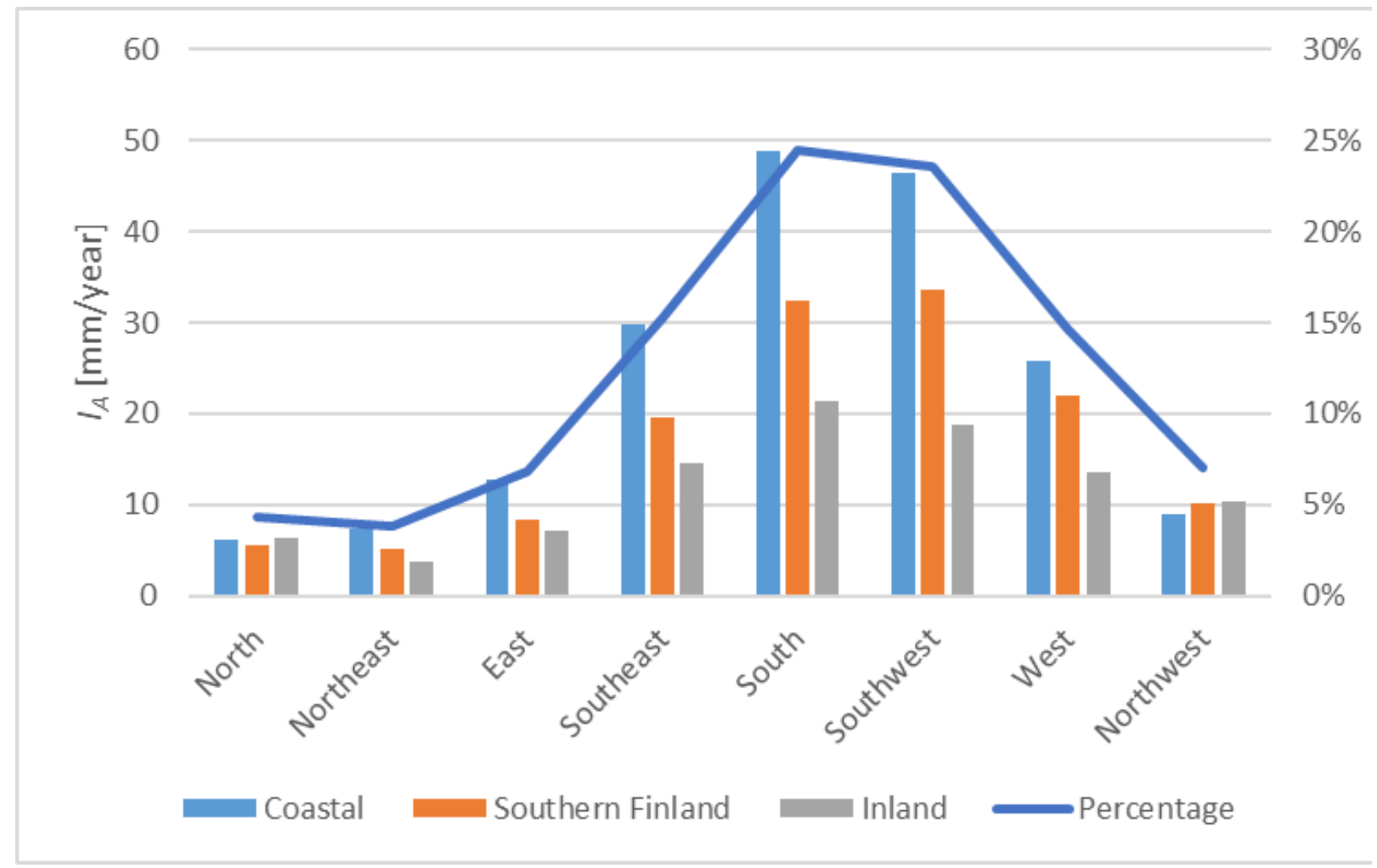

Figure 5 - Airfield annual index for up to three days before freeze-thaw cycles with a limit temperature of $-5^{\circ} \mathrm{C}$ from different directions at the three locations studied. 
As the results show, the amount of WDR and especially the amount of WDR before freeze-thaw events has a significant relation to freeze-thaw damage observations.

\section{2}

\section{Case building}

Based on condition investigation, the concrete used in the case building was of poor quality. The average protective pore ratio was 0.09 in facades and 0.06 in balcony side panels, which indicates that either there was no air-entrainment or it was unsuccessful. According to laboratory tests, $20 \%$ of the concrete core samples had visible cracking parallel to the surface, indicating freeze-thaw damage. It should be noted, however, that $7 \%$ of the samples were taken from the elements where far-advanced freeze-thaw damage had already been detected using NDT methods. The tensile strength of the façade samples varied between 0.84 and $2.15 \mathrm{MPa}$ and in samples taken from balcony structures between 0.61 and $2.77 \mathrm{MPa}$. Values under $1.00 \mathrm{MPa}$ are considered to possibly indicate freeze-thaw damage. One sample from façade- and three from balcony structures were below the value.

Approx. $25 \%$ of the façade area and $10 \%$ of balcony structures were investigated with hammering. Far-advanced freeze-thaw damage was detected only in approx. 3\% of the studied facade area but in almost half of the balcony structures studied, mainly side panels.

Figure 6 shows the amount of $I_{W A}$ on different parts of the facades, the hammering areas and the locations of the samples taken. Signs of freeze-thaw damage were detected:

- visually in facade sample no. 24 and balcony side panel sample no. 2

- in thin-section analysis in facade sample no. 26

- in tensile strength tests in facade samples nos. 8 and 27 and in balcony side panel samples nos. 2,10 and 23 .

No signs of freeze-thaw damage were found in balcony slabs or parapets. Compared to facade and side panel samples, parapets and slabs had a slightly higher protective pore ratio, an average 0.11 and 0.13 , respectively.

All the freeze-thaw damage indicated by visual observations, hammering or studies of the concrete core samples were located in areas where the total amount of $I_{W A}$ was over $21 \mathrm{~mm}$. The level of such WDR was achieved on north-west and north-east facades only on their top 2.5 meters. On south-east and south-west facades, the same level was reached already at the fourth floor, i.e. above 12 meters from the ground.

Almost all the freeze-thaw damage observations were made on the south-east- and south-westfacing facades or balconies. During the same 20-year time period, the total number of rain events followed by freeze-thaw cycles $\left(-5^{\circ} \mathrm{C}\right)$ were 161 from north-west-, 101 from north-east-, 192 from south-east- and 207 from south-west-oriented rain events. When only the airfield annual index $I_{A}$ (see Equation 3), i.e. the WDR in an open area, is calculated, the total amount of $I_{A}$ during the same time period was $123 \mathrm{~mm}, 132 \mathrm{~mm}, 479 \mathrm{~mm}$ and $489 \mathrm{~mm}$, respectively. Thus, the amount of WDR before a freeze-thaw cycle was significantly lower during the rain events from north-west and north-east directions while the number of cycles was lower. 
Nordic Concrete Research - Publ. No. NCR 61 - ISSUE 2 / 2019 - Article 6, pp. 91-106

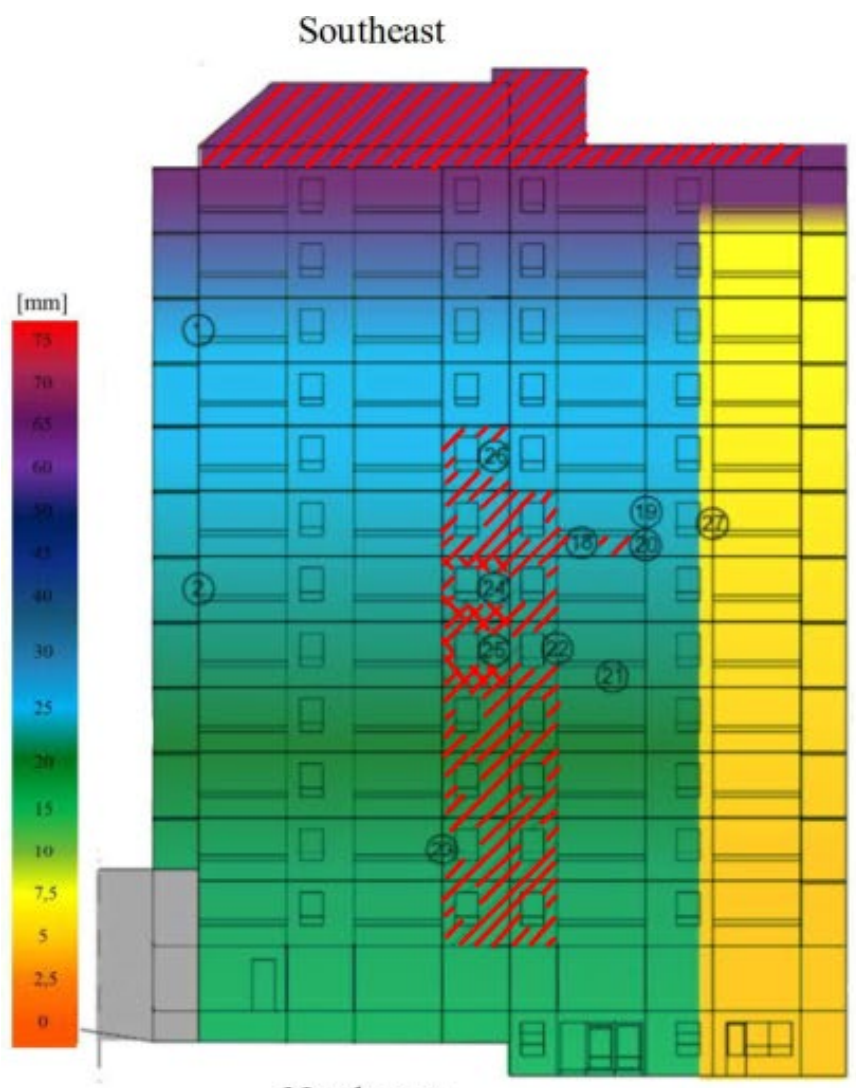

Northwest

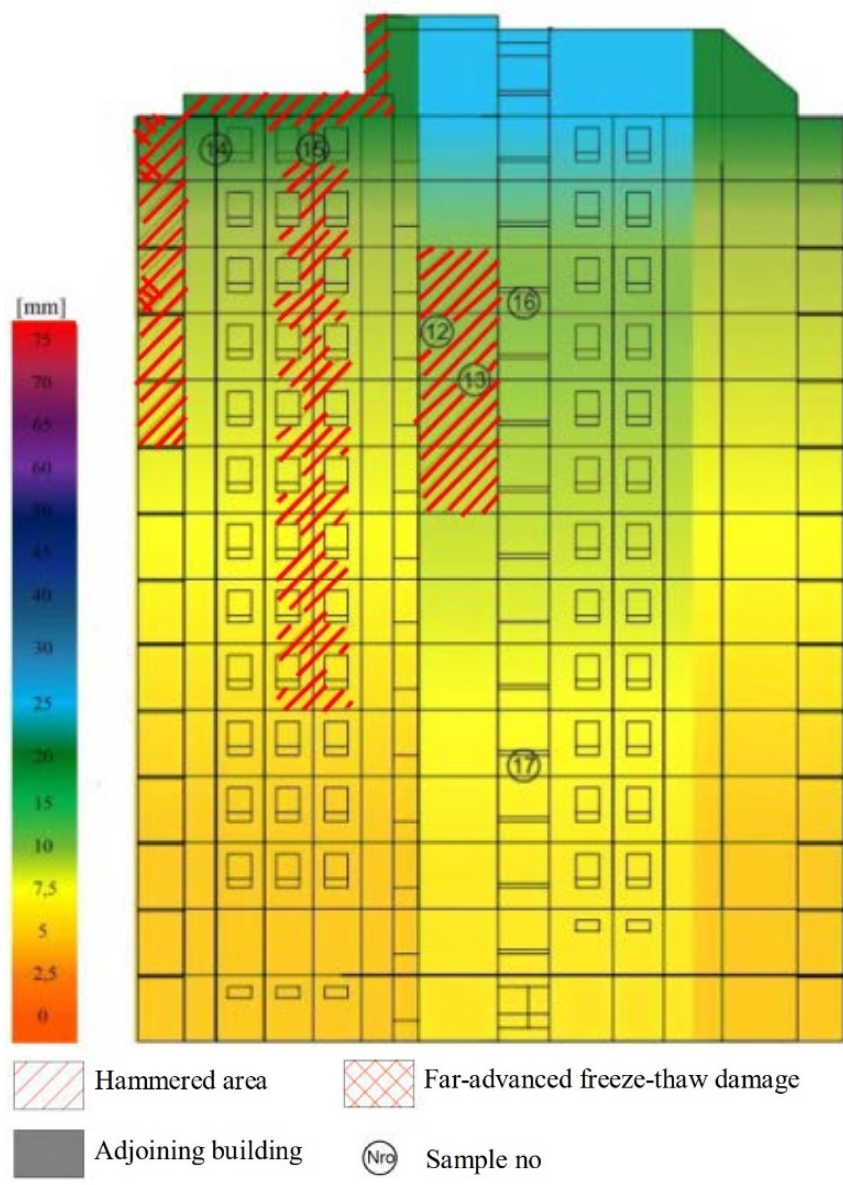

Southwest

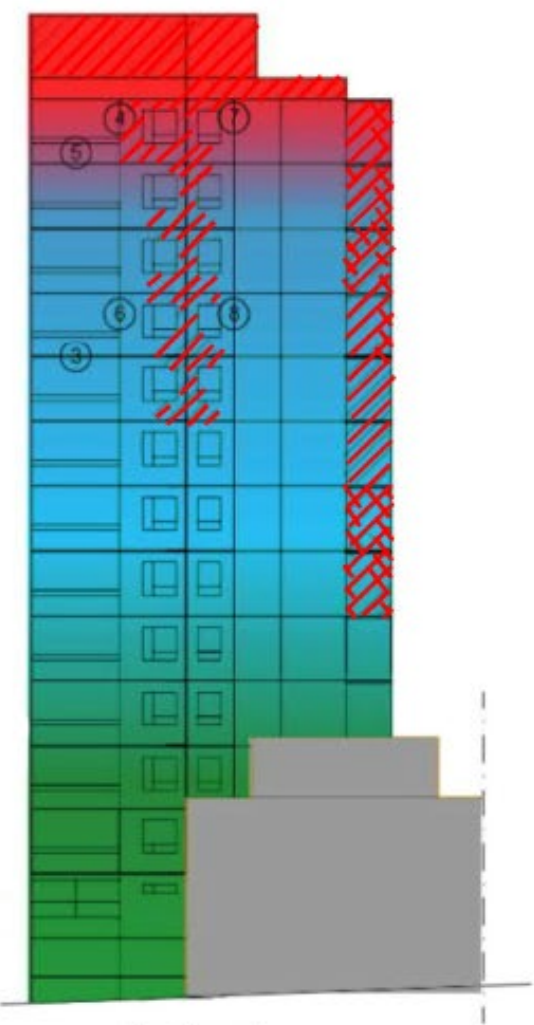

Northeast

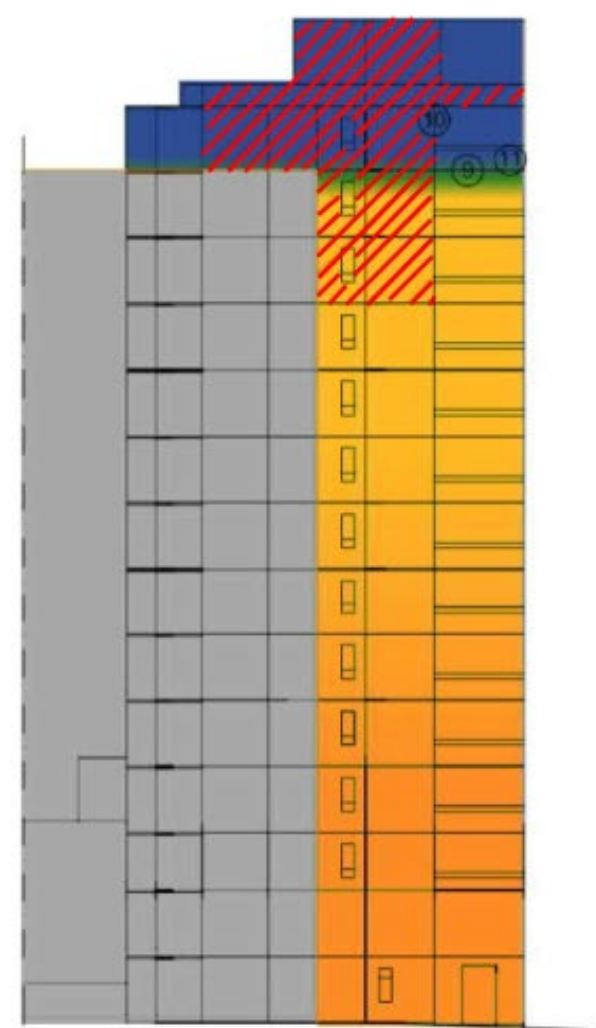

Figure 6 - Amount of $I_{W A}$ on different parts of the facades, hammering areas and locations of the taken samples. The numbers and colour gradation on left present the amount of WDR. 
The results indicate that both the amount of WDR itself and WDR before the freeze-thaw cycle have a major effect on the rate of detectable freeze-thaw damage. However, there were also facade and balcony structures with no detected freeze-thaw damage in the areas where the calculated amount of WDR was significantly high. There are many reasons explaining, such as:

- The quality difference with the used concrete and all the error sources related to the simplified calculation method.

- The location of the weather station beings quite far from the case building, though the used standard allows the distance to be less than $100 \mathrm{~km}$.

- The used method underestimates the amount of wind-driven rain near the top and corner parts of the facade, but overestimates the amount on the top 2.5 metres with high buildings and low rain intensity [18].

- The method does not take into account the topography of the structures (e.g. offset of the facade) nor the effect of adjoining buildings.

- The quality of the used concrete may vary significantly within the same building.

\section{5.}

\section{CONCLUSIONS}

In this study, a connection between the direction in which a concrete façade or balcony structures face, the amount of WDR on those structures and far-advanced freeze-thaw damage occurrence was studied by examining condition investigation reports more extensively than in previous studies. As an addition, a case building was studied in order to roughly observe the connection between WDR on different areas of the building and the observations made in the condition investigation of the building in question.

The first part of the study is based on condition investigation reports of 472 concrete-element buildings from which far-advanced freeze-thaw damage observations by hammering and visual inspection were gathered. A significant part of the observations in facades, $81 \%$, were made from the facades facing west, south-west, south or south-east. In the coastal area, the percentage is even higher, $88 \%$, and in inland lower, $71 \%$. In balconies, the percentage is again higher, although it must be noted that most of the balconies traditionally face western to southern directions to maximise the amount of sunlight.

In addition, the amount of WDR calculated as a standard-based Airfield annual index $\left(I_{A}\right)$ was studied. It shows that the connection between the orientation of freeze-thaw damage observations and the amount of WDR is clear. When the amount of WDR closely (up to three days) before a freeze-thaw cycle was studied, the connection is even more distinct.

With the case study building, the amount of WDR taking into account, for example, the close terrain and other buildings was calculated utilising the standard based Wall annual index $\left(I_{W A}\right)$. The amount of $I_{W A}$ on the different parts of the building erected in 1977 was calculated cumulatively starting from the year the data were available (1980) until the year of the condition investigation (1997). The results showed that almost all the freeze-thaw damage observations were made in the direction of the greatest climate load. The vertical level also has a great effect because the amount of WDR is higher at the top parts of the building.

The results of the study emphasise the significance of the orientation of outdoor exposed concrete structures when considering the freeze-thaw durability. The observation is even more significant 
for existing concrete structures with poor freeze-thaw properties. In addition, the case study presents that even a basic study of climatic load on a specific building could be used to make the condition investigation sampling more specific. Together, the results show that climatic stress studies, especially with the condition investigation data, can be used to plan protective methods and be a base for service life estimations.

\section{REFERENCES}

1. Lahdensivu J: "Durability Properties and Actual Deterioration of Finnish Concrete Facades and Balconies". TUT Publ. 1028. (PhD Thesis), Tampere University of Technology. Tampere, Finland, 2012, 117 p.

2. Pakkala T A, Köliö A, Lahdensivu J \& Kiviste M: "Durability demands related to frost attack for Finnish concrete buildings in changing climate", Building and Environment, Volume 82, December 2014, pp. 27-41.

3. Pakkala T A, Köliö A, Lahdensivu J \& Pentti M: "Predicted corrosion rate on outdoor exposed concrete structures", International Journal of Building Pathology and Adaptation, accepted 6 February 2019.

4. Köliö A, Pakkala T A, Hohti H, Laukkarinen A, Lahdensivu J, Mattila J \& Pentti M: "The corrosion rate in reinforced concrete facades exposed to outdoor environment", Materials and Structures, 50(1), 2016, pp. 1-16.

5. Lisø K R, Kvande T, Hygen H O, Thue J V, Harstveit K: “A frost decay exposure index for porous, mineral building materials", Building and Environment, 42(10), 2007, Pp. 35473555.

6. Finnish Concrete Association: "by 42 Condition investigation of concrete façade panels 2013”. (“by 42 Betonijulkisivun kuntotutkimus 2013”). Helsinki, Finland. (In Finnish).

7. Lahdensivu J, Varjonen S, Pakkala T \& Köliö A: "Systematic condition assessment of concrete facades and balconies exposed to outdoor climate", International Journal of Sustainable Building Technology and Urban Development, 4:3(2013), pp. 199-209.

8. Kuosa H \& Vesikari E: "Ensuring of concrete frost resistance Part 1: Basic data and service life design". ("Betonin pakkasenkestävyyden varmistaminen. Osa 1. Perusteet ja käyttöikämitoitus”). VTT Technical Research Centre of Finland, Research notes 2056, 2000, 141 p. (In Finnish).

9. Powers T C: "The air requirement of frost-resistant concrete". Chicago: Portland Cement Association, Research and Development laboratories, Development Department, Bulletin 33, 1949.

10. Litvan G: "Phase transitions of adsorbates IV - Mechanism of frost action in hardened cement paste". Journal of the American Ceramic Society 55 (1), 1972, pp. 38-42.

11. Pigeon M \& Pleau R: "Durability of concrete in cold climates". London. E \& FN Spon, $1995,244 \mathrm{p}$.

12. ASTM International: "ASTM C856-18a (2018) - Standard Practice for Petrographic Examination of Hardened Concrete". West Conshohocken, PA. 15 p.

13. Koskiahde A: "An experimental petrographic classification scheme for the condition assessment of concrete in facade panels and balconies". Materials Characterization, Vol. 53, 2014, pp. 327-334.

14. Shang H-S, Cao W-Q \& Wang B: "Effect of Fast Freeze-thaw Cycles on Mechanical Properties of Ordinary-Air-Entrained Concrete". The Scientific World Journal, 2014, 7 p. 
Nordic Concrete Research - Publ. No. NCR 61 - ISSUE 2 / 2019 - Article 6, pp. 91-106

15. Lahdensivu J, Varjonen S \& Köliö A: "Repair Strategies of Concrete Facades and Balconies". ("Betonijulkisivujen ja -parvekkeiden korjausstrategiat"). Tampere University of Technology, Department of Civil Engineering. Research report 148, 2010. (In Finnish).

16. Pakkala T A, Lemberg A-M, Lahdensivu J \& Pentti M: "Climate change effect on winddriven rain on facades". Nordic Concrete Research, Publication No. 54, 2016, pp. 31-49.

17. Finnish Standards Association SFS: "SFS-EN ISO 15927-3. 2009. Hygrothermal performance of buildings. Calculation and presentation of climatic data. Part 3: Calculation of a driving rain index for vertical surfaces from hourly wind and rain data". Helsinki, Finland, 2009.

18. Blocken B. \& Carmeliet J: "Overview of three state-of-the-art wind-driven rain assessment models and comparison based on model theory". Building and Environment, Volume 45 (2010), pp. 691-703. 